\title{
Ser pontual num encontro que só pode falhar. Notas sobre a contemporaneidade do artista
}

\begin{abstract}
RESUMO: Este artigo pretende ser um contributo para a discussão sobre o que é a contemporaneidade do artista. Não se trata tanto de responder à pergunta o que é a arte contemporânea, mas tentar identificar as razões pelas quais o modo de pensar cronológico é insuficiente para compreender a forma como os artistas estabelecem relações com o todo da história e do tempo. Uma relação que se descobre ser dialéctica e, seguindo as importantes sugestões de Didi-Huberman e Claire Bishop, anacrónica. Trata-se de uma caracterização da contemporaneidade motivada pelo modo como as próprias obras são objectos detentores de uma temporalidade própria que exige aproximações, experiências e leituras diferentes das usadas habitualmente para ler os factos do mundo. Primeiro descobre-se que o tempo da arte é lugar de intensidades e que cada artista entende a história não como o desenrolar linear de obras e artistas, mas como lugares simultaneamente presentes de que a cada momento se podem aproximar e apropriar. Depois, compreende-se que a contemporaneidade é, sobretudo, um método de pensar e produzir conhecimento e arte que se caracteriza por ser dialéctico. Finalmente, a relação dos artistas com o seu tempo é um lugar de tensão porque não podem escapar ao encontro que têm marcado com o seu próprio tempo (um artista é de um tempo e pertence a uma época), mas esse é um encontro, como veremos
\end{abstract}

\footnotetext{
* Nuno Crespo é doutor em filosofia e pesquisador na Universidade Nova de Lisboa onde também é professor convidado do departamento de História da Arte onde ensina estética e coordena o curso de curadoria de arte. Publicou Wittgenstein e a Estética (edt. Assírio \& Alvim) e Julião Sarmento. Olhar Animal. É crítico de arte do Jornal Público e curador independente.
} 
com Agamben e o escultor português Rui Chafes, destinado a falhar, porque a arte é lugar de interrupção e de intervalo e nunca um lugar coincidente com as luzes que iluminam uma dada época e, depois, porque os artistas são aqueles que fixam o olhar no escuro e nas sombras do seu presente fazendo dessa escuridão um elemento essêncial da sua temporaneidade.

PALAVRAS-CHAVE: contemporaneidade artistica, anacronia, tempo da arte.

\section{Mote}

A contemporaneidade na arte é a influência dos melhores sobre os melhores, quer dizer, o contrário da actualidade: influência dos piores sobre os piores. $O$ jornal de amanhã já envelheceu. O que implica que a maioria dos acusados de "contemporaneidade" não merece tal acusação, já que apenas sofre de "temporaneidade", um conceito tão oposto ao de contemporaneidade como ao de "extratemporaneidade». Contemporâneo: omni-temporâneo. Qual de nós virá a ser nosso contemporâneo? Algo que apenas pode ser constatado pelo futuro e somente é certo no passado. Os contemporâneos são sempre uma minoria. (TSVIETAIEVA, 1993, p.71-72).

Este texto pretende ser um contributo para a definição do conceito de contemporaneidade artística. Não se trata de uma abordagem histórica, mas o objectivo é, a partir do contributo de Agamben, Bishop, Didi-Huberman, Pelbart e Rui Chafes, discutir o modo como a contemporaneidade é construída não a partir de certas condições temporais cronológicas, mas diz respeito a um certo modo de organizar a história e de o sujeito (aqui o sujeito artístico) pensar-se a si próprio no contexto dessa mesma história. Assumimos o conceito de contemporaneidade como uma categoria temporal, mas no sentido daquele tempo que surge materialmente contido, articulado e montado nas construções materiais dos artistas, isto é, nas obras de arte. A discussão que propomos é conceptual e estética e não é relativa a princípios ou metodologias do campo disciplinar da história. Em rigor trata-se de pensar a contemporaneidade não como uma categoria histórico-cronológica, mas como uma experiência particular do tempo e da memória tal como surge proposta nas obras dos artistas contemporâneos. E aqui não no sentido de tentar fixar uma definição unívoca da expressão arte contemporânea, ou seja, não 
nos move a pergunta o que é a arte contemporânea?, mas a inquietação em saber o que é que constitui a contemporaneidade do artista? Qual é o seu tempo? Em que direcção move o seu olhar? Quais os lugares temporais onde fixa a sua percepção e que constituem as suas instâncias principais da sua aprendizagem? Sendo que esta aprendizagem, no sentido que aqui Ihe damos, não é relativa a nenhum tipo de pedagogia artística formal, mas convoca a ideia de biografia intelectual e artística não só como forma de desenvolvimento de certa personalidade e singularidade artísticas, mas também assume essa mesma biografia como proposta de leitura crítica do tempo, da tradição e da história.

\section{O tempo da arte é um tempo sem medida}

Na tentativa de mostrar a abrangência problemática detida pela pergunta sobre o contemporâneo, Peter Pelbar retoma a distinção grega entre Chronos e Aion para mostrar como, do ponto de vista artístico, o tempo não pode ser entendido como de um ponto de vista cronológico, porque ele é sem medida. A premissa é que o tempo da arte não constitui nenhuma possibilidade de medir o tempo, mas designa uma intensidade porque se trata de um tempo indefinido, infinito, subjectivo e sentimental:

\footnotetext{
Time without measure, indefinite, never ceasing to divide itself; always already there (the imemorial) and not yet there (the unprecendented); always to too early and too late; the time of the 'something is going to happen' and simmutaneously the 'something just happened'; the outprint of forked, non-metric, non-vibrating, fluctuating time we sometimes see in psychosis, in dreams, in catastrophes, in large and in microscopic ruptures, whether collective or individual. (PELBART, 2015, p. 10).
}

A questão de Pelbar não é o tempo tal como surge no pensamento filosófico, mas o modo como o tempo se expressa nas obras de arte e é esse tempo, que permanentemente se reinventa, reconstrói e refaz, não mensurável, nem linear que importa perceber. O texto mostra que o tempo da arte é feito do encontro - umas vezes harmonioso e em outras assumindo a formas de ruptura, de confronto ou de catástrofe - com um tempo precedente e outro antecedente. Ou seja, está entre o imemorial e o inaudito [unprecedented] e implica convocar uma espécie de singularidade temporal sem precedentes. É como se cada obra de arte inaugurasse um novo tempo e, através desse gesto inaugural, operasse uma ruptura no tecido da habitual linearidade temporal. 
Mas a caracterização da contemporaneidade feita no texto faz-se através de um importante contraste com a modernidade, nomeadamente a partir do modo como Deleuze e Guattari pensam a questão do moderno versus contemporâneo e como usam a esquizofrenia como estratégia filosófica para caracterizar o aspecto problemático da relação contemporânea com o tempo. E trata-se de uma relação problemática porque, usando as palavras de Straub citadas por Pélbart, o tempo presente, que nos foi roubado em nome do progresso, passa e é irrecuperável. E é este sentimento de perda - perda não só relativa à passagem do tempo, mas a perda da contemporaneidade caracteriza-se pela ausência de utopias politicas, sociais, culturais e tecnológicas. Se a modernidade se pode caracterizar por um optimismo contagiante crente no desenvolvimento humano, material e social da sociedade, a contemporaneidade marca-se pela ausência desse pensamento positivo o qual dá lugar a profunda descrença e a um viver esquizofrénico num tempo do qual não se quer fazer parte: como se nos afundássemos num tempo que não queremos que seja o nosso.

Para a discussão do nosso argumento não interessa desenvolver a oposição e distinção entre moderno e contemporâneo, mas salientar a complexidade temporal que o conceito de contemporaneidade artística implica a qual, é este o argumento do nosso texto, resulta do modo extraordinário como o tempo se articula nas obras de arte, o que, por sua vez, é consequência da forma como os artistas olham para história e constroem o seu olhar e a sua sensibilidade.

Em suma, segundo esta justa caracterização a contemporaneidade é marcada por uma complexa relação com o tempo a qual é, como vimos, flutuante, híbrida e, como Claire Bishop a descreve, dialéctica (BISHOP, 2014). A discussão da historiadora inglesa está centrada na questão dos museus e no modo como a sua programação reflecte não só a condição de contemporaneidade de alguns museus, mas igualmente a maneira como esses práticas museológicas e curatoriais são fruto de um entendimento do que são as dinâmicas criativas e as experiências e conhecimentos que produzem. Se com Pelbart a contemporaneidade artística surge ligada a uma percepção e compreensão particulares do tempo, com Bishop descobre-se a contemporaneidade enquanto método dialéctico.

\section{A contemporaneidade como método dialéctico}

Num breve estudo sobre três museus europeus, Claire Bishop tenta responder à questão do que é que é contemporâneo nos museus contemporâneos: a pergunta presente no subtítulo do texto é muito clara 'what is contemporary in contemporary art museums?' (BISHOP, 2014). 
Ainda que a sua análise se centre especificamente na questão das práticas museológicas, o texto começa por fazer uma identificação das modalidades temporais e artísticas a que corresponde à categoria do contemporâneo. Desfazendo todas as confusões entre contemporaneidade e presentismo ${ }^{1}$ [presentism], Bishop propõe ver na contemporaneidade artística um método dialéctico: portanto, não se trata de um estilo, uma temporalidade específica, período ou disciplina, mas está em causa nesta categoria artística um modo de perceber, fazer e expor arte que transforma a quietude contemplativa dos museus em lugares de convergência, encontro e discussão. O trabalho conceptual feito por Bishop destina-se a questionar se a contemporaneidade resulta unicamente da contaminação da arte pelo liberalismo económico e social dominante no mundo ocidental que exige museus contemporâneos como ícones das economias e lógicas de atracção do turismo ou se, pelo contrário, corresponde a novas modalidades de compreender, fazer e experimentar arte.

A fertilidade do argumento de Bishop é que desfaz qualquer ideia de continuidade ou estilo comum e faz da contemporaneidade um lugar de multiplicidades e singularidades artísticas e políticas. O aspecto político é decisivo para a historiadora e a sua concepção da contemporaneidade, tal como expressa nas práticas museológicas dos três museus que decide estudar, distingue-se tanto do argumento da 'ficção operativa' de Peter Osborne, como de Boris Groys e da sua concepção da contemporaneidade como tempo suspenso e sem futuro devido ao adiamento da utopia que o fim do comunismo tornou presente; e, finalmente, de DidiHuberman e da sua proposta da contemporaneidade como anacronismo (voltaremos a este aspecto mais tarde).

A articulação da política através do tempo é decisiva na proposta de Bishop da contemporaneidade como método dialéctico:

Aquilo a que chamo contemporaneidade dialéctica procura navegar através de múltiplas temporalidades dentro de um horizonte político. Em vez de afirmar que muitos ou que todos os tempos estão presentes em cada um dos objectos históricos, precisamos perguntar por que é que certas temporalidades aparecem em obras de arte particulares como momentos históricos específicos. Para além disso, esta análise é motivada pelo desejo de compreender a nossa condição presente e de encontrar formas de como a mudar [...]. O objectivo final é romper com o pluralismo relativista do nosso momento actual, no qual todos os estilos e crenças são considerados igualmente válidos, e avançar para uma forte compreensão política do lugar para 
onde podemos e devemos dirigir-nos. Se, como Osborne afirma, a contemporaneidade global é uma ficção partilhada, isto não implica a sua impossibilidade, mas pelo contrário fornece a base para um novo imaginário político (BISHOP, 2014, p.23)².

Para o objectivo do nosso texto - determinar a complexidade e o anacronismo da contemporaneidade do artista - importa perceber o papel essêncial detido pela arte e pelos artistas contemporâneos na reconfiguração do nosso pensamento sobre o mundo. E podem fazê-lo porque as obras de arte, tal como apresentadas e integradas em certos museus, são instâncias de renovação do nosso imaginário político, reavaliando, revendo, energizando, discutindo, as utopias, ideias, conceitos e práticas políticas. O texto de Bishop tenta mostrar como o museu contemporâneo, pelo menos nos três casos por ela discutidos, serve não só como instância de fabricação da história e dos seus objectos temporais, mas igualmente são modelos materiais de uma história não hegemónica. O museu contemporâneo é aquele que não reflecte as lógicas de mercado, mas é o locus, pelo menos é esta a exigência ética, política e artística da autora, onde o espectador contacta com visões do mundo, posições sociais, politicas, culturais e lógicas sensíveis a que pode aderir ou contestar, assumir ou recusar, discutir, agir e contemplar. Desta forma, o museu na sua dimensão antiaurática, antiobjeto, antimercado, antimodelo capitalista, torna-se um agente histórico de transformação individual e fá-lo através de um trabalho continuo de justaposição entre as obras de arte e outras "coisas" e práticas consideradas não artísticas. Por isso, a sua conclusão é que a contemporaneidade não é relativa a nenhum tipo de cronologia ou temporalidade específica, mas é uma prática e um método potencialmente aplicáveis a todos os tempos e a toda a arte (BISHOP, 2014, p.59) ${ }^{3}$.

A possibilidade metodológica apresentada pode resumir-se desta forma: a arte contemporânea, dada a sua não linearidade temporal (e neste aspecto da desmedida do tempo Pelbart e Bishop concordam), significa antes de mais a possibilidade de cruzar muitas camadas de tempo (é útil pensar aqui na ideia de Abby Warburg de montagem como possibilidade espistemológica) e, a partir dessa capacidade de navegação e cruzamento, constitui uma possibilidade de reconfiguração dos objectos históricos e, por consequência, as práticas criativas e expositivas caracterizam-se, segundo Bishop, pelo esforço de traçar a fisionomia do presente. Esta fisionomia é temporal e é caracterizada por uma dinâmica anacrónica, ou seja, o presente artístico é um lugar de contaminação que se desenvolve num horizonte não cronológico contendo a possibilidade de realizar múltiplos cruzamentos, sínteses, colagens e junções. Por 
isso é que Didi-Huberman quando tenta pensar a história da arte propõe uma metodologia atemporal e, seguindo Warburg, patológica procurando lógicas de influências e contaminações e não filiações ou cronologias. E trata-se de um campo anacrónico porque as obras dos artistas não são agentes cronológicos, mas pelo contrário, constituem-se enquanto objectos temporais anacrónicos que provocam uma permanente transformação do tempo, da história, do nosso saber e do nosso sentir.

\section{O tempo da arte como complexidade anacrónica}

O conceito de complexidade anacrónica surge em Didi-Huberman (DIDI-HUBERMAN, 2000) como forma de pensar uma nova metodologia para o campo da história da arte e fá-lo através de um deslocamento da disciplina da sua definição enquanto campo estritamente histórico para um terreno em que o enunciado da temporalidade é intensamente questionado. Não nos importa aqui explorar as consequências que a apresentação da história da arte como disciplina anacrónica possui, mas sim mostrar que essa visão - que é uma exigência metodológica resulta da própria natureza das obras de arte. Se a abordagem canónica da história é eucrónica [euchronique] porque assente numa concepção linear do tempo, a arte é diacrónica, ou seja, as obras de arte são objectos temporais complexos com uma estrutura interna construída através do cruzamento de diferentes camadas de tempo que tornam as obras de arte em objectos exuberantes e complexos:

Reconnaître comme une richesse la nécessité de l'anachronisme: elle semble interne aux objets mêmes — les images — don't nous tentons de faire l'histoire. L'anachronisme serait ainsit, en toute première approximation, la façon temporelle d'exprimer l'exubérance, la complexité, la surdétermination des images (DIDI-HUBERMAN, 2000, p.16).

O anacronismo das imagens - a que podemos fazer equivaler o anacronismo de toda a arte - é a expressão da sobredeterminação temporal das imagens: uma obra de arte é, do ponto de vista temporal, uma extraordinária montagem de tempos heterogéneos. Esta possibilidade de convivência de múltiplos tempos, garantida pela plasticidade fundamental das obras de arte permite a mistura de muitos diferenciais, segundo a boa expressão do historiador francês, que resiste a interpretações, classificações e à fácil integração em sistemas explicativos da arte e da sua história. 
O esforço em causa no texto de Didi-Huberman é tornar evidente que a 're-definição' da história da arte como disciplina anacrónica decorre do modo como o trabalho artístico segue uma metodologia que, fazendo uso de sobreposições, organiza o tempo diferencialmente, ou seja, os seus princípios não são lineares ou causais e é dessa forma que organiza a memória do sujeito artístico - a partir do presente — e da própria arte: cada obra de arte dirige-se não ao seu tempo, mas ao todo da história, aos vivos e aos mortos ou, na formula de Jean Genet no seu texto sobre Giacometti, à imensa comunidade dos mortos. É neste contexto que DidiHuberman fala de uma soberania do anacronismo [souveraineté de l'anachronisme] e mostra como cada imagem não só conjuga uma imensidade de tempos diferenciais, como também implica o todo da história, do tempo, da arte:

Il faut comprendre qu'en chaque objet historique tous le temps se reencontre, entrent en collision ou bien se fodent plastiquement les uns dans les autres, bifurquent ou bien s'enchevêtrent les uns aux autrres. (DIDI-HUBERMAN, 2000, p.43).

Ainda que o estudo de Didi-Huberman seja acerca da singularidade e do estatuto epistemológico da história da arte, claramente contaminado pela filosofia da história de Walter Benjamin, pela ideia de sobrevivência das imagens de Abby Warburg e pela inquietação em saber como pode o historiador fazer justiça à singularidade temporal da arte, os seus argumentos tornam evidente que a anacronia por ele proposta como matriz do conhecimento e pensamento acerca da arte não é uma invenção metodológica, mas decorre da natureza própria da temporalidade inerente a cada objecto artístico.

\section{O contemporâneo é o inactual}

Se anteriormente vimos como o tempo da arte é um tempo sem medida, importa agora perceber como é que o sujeito artístico se localiza face ao tempo. Na citação que constitui o mote deste ensaio, a poetisa Marina Tsvietaieva, antecipando as principais teses defendidas por Giorgio Agamben no seu famoso ensaio O que é o contemporâneo?, inicia o seu argumento (que não é um argumento filosófico ou histórico, mas poético) através do estabelecimento de uma oposição e contraste entre contemporaneidade, actualidade e temporaneidade. Sendo:

Actualidade: influência dos piores sobre os piores

Temporaneidade: sofrer a acção do tempo 
Contemporaneidade: influência dos melhores sobre os melhores

Contemporoneidade: omni-temporâneo

Estas distinções não são retóricas, nem cronológicas, mas é expressão de uma compreensão do que significa para o poeta ser contemporâneo e a maneira como, através de uma muito partícular compreensão do tempo da poesia, cada poeta e cada poema constroem a sua contemporaneidade. Para a poetisa, está em causa uma evidência que não diz respeito ao tempo ou à história enquanto factos exteriores e distantes do sujeito artístico e das duas obras, mas a certo modo de ser afectado pelo tempo poético o qual, como ela escreve, é omni-temporâneo, ou seja, o tempo poético é sempre o TODO da poesia, sem cronologia, que o poeta transporta, como se cada novo poema contivesse e, simultaneamente, afectasse TODA a poesia. Por isso, ser contemporâneo é uma forma de afecção, ou seja, é o modo de ser afectado, ferido e atingido por algo distante ou próximo, antigo, futuro ou passado, nunca por aquilo que é presente e imediato.

Ainda que não seja explícito o modo como esta compreensão da contemporaneidade poética pressupõe uma relação do poema com a história da poesia idêntica à que vimos para a arte, pode pressupor-se que o poema, como a obra de arte, é um objecto anacrónico que encerra, cruza e conjuga diferentes tempos. E o que é importante na apresentação de Tsvietaieva é o modo como a contemporaneidade não é vista à luz da actualidade ou da capacidade poética em falar ao seu tempo e do seu tempo, o que seria uma espécie de popularidade, mas corresponde a uma forma de isolamento e, por isso, os contemporâneos são uma minoria. Pode até pensar-se que o ser contemporâneo é para o artista uma forma de inactualidade. No sentido em que ser inactual significa sentir a desconexão e o desfasamento relativamente ao seu presente, à sua actualidade ou, como diz Tsvietaieva, à sua temporaneidade.

O desencontro da arte e do artista com o seu tempo que marcam a contemporaneidade artística, é uma forma de inactualidade porque o artista tem relativamente ao seu tempo um distanciamento e entende a realidade de um modo distinto da maioria dos seus contemporâneos:

Aquele que pertence deveras ao seu tempo, que é deveras contemporâneo é alguém que não coincide verdadeiramente com ele nem se adapta às suas exigências e é por isso, nesse sentido, inactual; mas, precisamente por isso, precisamente através do seu distanciamento e do seu anacronismo, é capaz de perceber e captar o seu tempo melhor do que outros (AGAMBEN, 2010, p.20). 
Esta é uma inactualidade nietzscheana porque não corresponde a uma forma de alheamento do tempo e da realidade, mas corresponde a uma espécie de categoria existêncial intempestiva, diria Nietzsche, a qual consiste em compreender o seu tempo como um mal. Ver o presente como um mal implica vê-lo à distância o que se consegue através de uma ginástica visual, sentimental e intelectual que passam a constituir a modalidade da atenção artística sobre o presente. A esta luz ser contemporâneo é, critica e intempestivamente, fixar o seu olhar sobre o presente - a actualidade - não para Ihe aderir e para com ela coincidir, mas, pelo contrário, para se poder distanciar do seu tempo. Escreve Agamben:

Os que coincidem demasiado plenamente com a época, que condizem em todos os pontos perfeitamente com ela, não são contemporâneos, porque, precisamente por isso, não conseguem vê-la, não podem fixar o olhar sobre ela (AGAMBEN, 2010, p.20).

E umas páginas à frente acrescenta:

O contemporâneo é alguém que fixa o olhar no seu tempo, para perceber não as suas luzes, mas o seu escuro. Todos os tempos são, para quem experimenta a sua contemporaneidade, tempos obscuros. O contemporâneo é, precisamente, aquele que sabe ver essa obscuridade, que é capaz de escrever mergulhando o aparo na treva do presente (AGAMBEN, 2010, p.22).

Esta obscuridade essencial do presente, a partir da qual o poeta escreve e o artista cria, não é combatida, nem constitui um ponto de cegueira, mas ver a escuridão é um movimento essêncial na construção da contemporaneidade artística: estar num tempo e não poder coincidir com ele designa a posição temporal - a que corresponde um estado de ânimo e uma dinâmica criativa — onde se situa o artista. E a sua acção própria é ver a escuridão da sua temporaneidade.

\section{Ver a escuridão}

Perceber o escuro do seu tempo não resulta da ambição em iluminar todo o presente anulando os seus campos de escondimento, as suas sombras pondo tudo às claras. Pelo contrário implica manter essa escuridão porque é nessas zonas sem luz que se pode ver e ouvir o que vem do tempo e se dá no tempo: a história, a nossa herança, os antepassados. Ver a escuridão e concentrar a atenção nas trevas da sua época não corresponde a uma espécie 
de cegueira voluntária, nem tão pouco é uma forma de inércia ou passividade, mas implica a intensa actividade de, como diz Agamben, neutralizar as luzes da sua época porque estas sim são pontos de cegueira e inebriamento que impedem as luzes que atravessam o universo de nos atingir. Tanto no caso de Tsvietaieva, como no caso de Agamben, acentuar da descoincidência do contemporâneo com o seu tempo não corresponde a uma visão conservadora e ortodoxa da história da arte e das práticas poéticas e artísticas, mas é o reconhecimento que o presente contém em si uma obscuridade essencial e é sobre esta obscuridade de que se desenvolve a arte.

Aquilo que percebemos como o escuro do céu é esta luz que viaja velocíssima direita a nós e, todavia não pode alcançar-nos, porque as galáxias de onde provém se afastam a uma velocidade superior à da luz. [...] Perceber no escuro do presente esta luz que procura alcançar-nos e não pode fazê-lo, eis o que significa sermos contemporâneos. É por isso que os contemporâneos são raros. E é por isso que sermos contemporâneos é, antes do mais, uma questão de coragem: porque significa sermos não só de fixar o olhar no escuro da época, mas também de perceber nesse mesmo escuro uma luz que, dirigindo-se a nós, se afasta infinitamente de nós. Quer dizer ainda: sermos pontuais num encontro que só pode falhar (AGAMBEN, 2010, p.24).

Haveria muito a dizer sobre o conceito de escuro e obscuridade e o papel que ocupa enquanto elemento de caracterização da relação do artista com o seu tempo, mas para o que nos interessa importa reter que as luzes que chegam ao presente não podem alcançar-nos e há uma espécie de fractura no tempo a qual, seguindo a boa sugestão de Agamben, é ocupada pelo artista. Uma fractura que o artista tenta a cada momento reconstruir e, por isso e como vimos anteriormente, é sempre todo o tempo e toda a arte que o artista tem diante de si enquanto material de trabalho e que torna actuante em cada uma das suas obras.

O reconhecimento do presente como mal e fractura, não implica que o artista, bem como cada um dos habitantes da Terra, fique dispensado do encontro que tem marcado com o seu tempo: é-se irremediavelmente de um tempo do qual não se pode escapar ou evadir, mas o nosso tempo é um tempo com o qual nunca poderemos inteiramente coincidir, porque a contemporaneidade, no sentido forte e distinto da temporaneidade, implica o deslocamento do sujeito artístico para a fractura temporal existente no presente por ser só aí que ele pode ser atingido por uma luz que vem de longe e que atravessa diferentes camadas de tempo. E receber esta luz constitui a condição de toda a arte, porque ela significa reconhecer as origens arcaicas, 
distantes, temporais, do presente. E é este elemento temporal anacrónico detido pelas obras que, segundo Didi-Huberman, marca a plasticidade essencial de todo o gesto poético a qual encontra na procura da origem arcaica de todo o acontecimento presente a sua metodologia.

A descoberta de haver algo que, à distância, nos procura atingir e para onde o artista dirige a sua atenção, não implica uma arte reprodutora de modelos, mas constitui a actividade crítica de descobrir a origem - Arche — de toda a forma presente. O elemento decisivo não é a fixação de uma temporalidade unívoca de certas modalidades artisticas: esta origem não designa um lugar histórico, nem um antepassado cronológico, mas é um elemento vivo que não cessa de agir no tempo tal como, usando a metáfora de Agamben, o embrião continua a agir nos tecidos do organismo maduro e a criança na vida psíquica do adulto. Chegar perto da origem é para um artista imitar, integrar e transformar os gestos originários, estabelecendo de cada vez uma genealogia da forma, da matéria e da sensibilidade. Esta acção poética e sentimental, que também é um modelo pedagógico, de 'ir ter com os mestres' deve ser entendida como uma regressão a partir da qual o artista constrói o seu tempo, ou seja, a maneira como livremente se relaciona com o seu passado é o que constitui a sua actualidade e a sua temporaneidade: é esse o seu tempo.

Como diz Agamben, trata-se de avançar para junto

daquilo que no presente em caso algum podemos viver e que, permanecendo não vivido, é incessantemente sorvido de novo na direcção da origem, sem nunca poder alcançá-la (AGAMBEN, 2010, p.27).

Trata-se de uma des-homegeneidade essêncial do tempo que é matéria de trabalho para o artista, porque a sua actividade, como temos vindo a insistir, não é só diagnosticar a fractura do tempo onde habita, mas sim a partir da obscuridade inerente a todo o presente transformar o todo do tempo:

O contemporâneo não é somente aquele que, percebendo o escuro do presente, capta a sua luz invendável; é também alguém que, dividindo e interpolando o tempo, está em condições de o transformar e de o pôr em relação com os outros tempos, de ler de modo inédito a sua história (AGAMBEN, 2010, p.28).

Podíamos resumir o percurso que estivemos a fazer dizendo que a contemporaneidade artística é constituída através da concentração da atenção do artista nas trevas do seu tempo e dessa acção de conjugação de diferentes camadas do tempo surgem objectos temporais as obras de arte — que propõe modos inéditos de ler a história. 


\section{Rui Chafes e o encontro secreto entre o moderno e o arcaico}

Há um caso artístico em que todas estas questões sobre a temporalidade artística e sobre o modo como o artista percebe o seu tempo são postas à vista. Num texto curto, intenso e exemplar, o escultor português Rui Chafes dá conta da História da minha vida (CHAFES, 2012) e a sua é uma história longa que não obedece a nenhum esquema integrador de factos, obras e artistas, mas é um percurso temporal feito livremente pelo próprio artista no sentido em que Rui Chafes constrói o seu tempo e, por consequência, é ele que estabelece a sua contemporaneidade e dessa forma o seu presente. O título do texto não é um programa, mas é uma descrição fiel do movimento que o escultor realiza: contar a sua vida é realizar uma espécie de autobiografia artística e intelectual através da qual o escultor mostra os diferentes tempos conjugados e articulados pela sua obra.

Importa advertir que para este escultor português a escultura é feita de ferro (o material exclusivo da concretização espacial e objectual das suas esculturas), fogo (que molda o ferro) e palavras (os títulos são sempre ingredientes fundamentais das suas obras). É neste contexto que a palavra dita e escrita (Rui Chafes traduziu uma selecção de fragmentos de Novalis e tem publicado textos da sua autoria) tem um papel central nas suas obras fazendo parte do seu universo criativo, plástico e escultórico. Por isso, será correcto entender o texto referido como um projecto artístico em que o artista realiza uma viagem através do seu tempo e estabelece as coordenadas temporais a partir das quais podemos ler a sua história que é a história da aprendizagem e desenvolvimento da sua escultura.

A abertura do texto é, desde logo, uma indicação do tempo — da cronologia artística - que este texto atravessa:

Nasci em 1266 numa pequena aldeia, que já não existe, na Francónia, na Baviera. Os meus pais eram muito pobres, de uma família de camponeses e artesãos, e a vida era extremamente difícil; também hoje a vida continua a ser difícil, mas de outra maneira e com outro tipo de privações e durezas (CHAFES, 2012, p. 11).

O nascimento de Chafes dá-se no momento em que se desenvolvem as primeiras esculturas que o constroem como artista e que passados 745 anos (o texto é datado de 2011) mantêm-se actuantes e lugares energéticos que se repercutem não só no modo como o escultor pensa a escultura e constrói a sua história artístico-intelectual, mas também enquanto elementos vitais que alimentam os gestos quotidianos da escultura. 


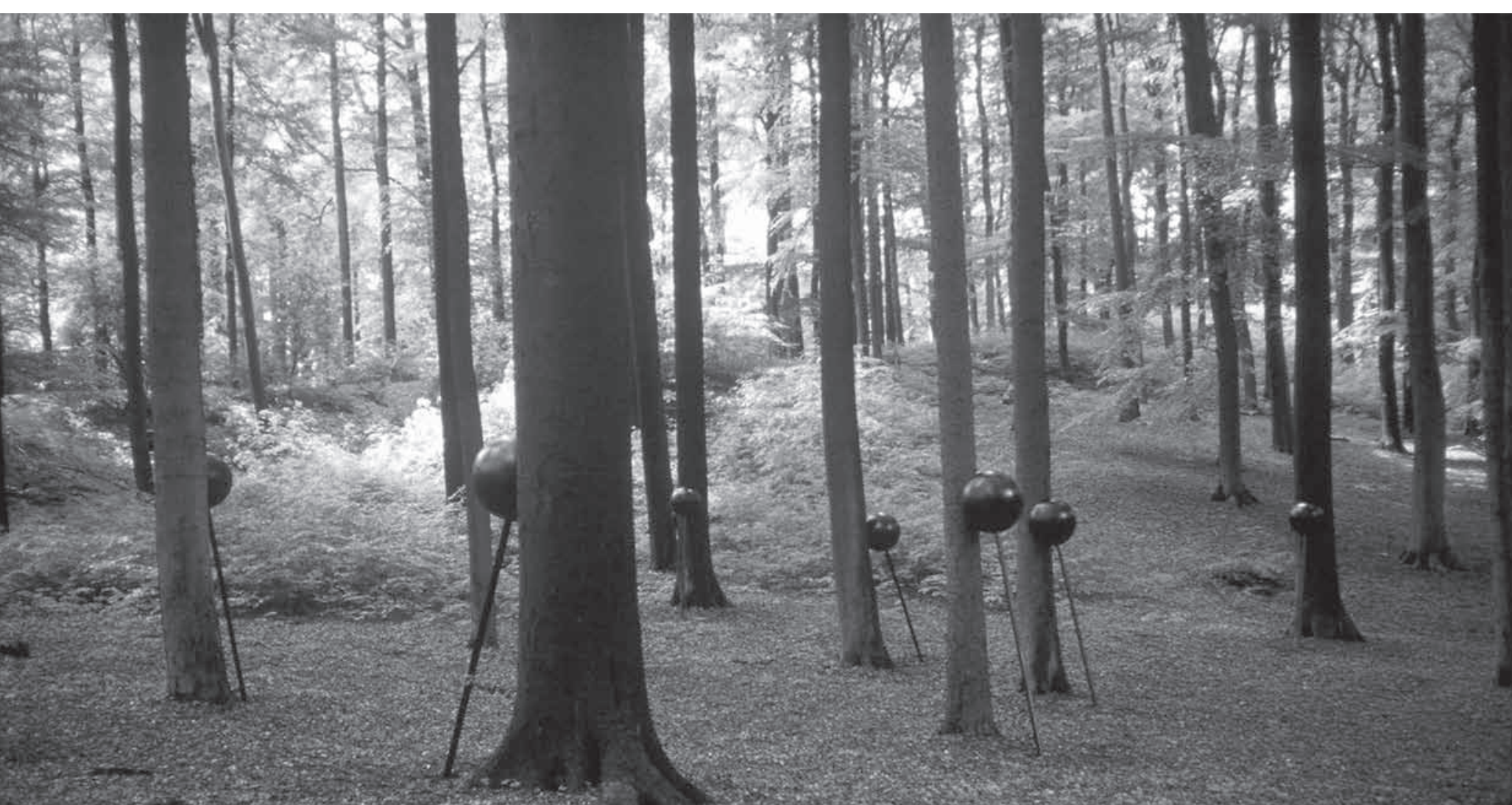

+3.

\section{Rui Chafes}

Unborn, 2001

Ferro, 9 esculturas, cada: $325 \times 65 \times 65 \mathrm{~cm}$

Col. Particular, Arnhem (Holanda) 
Aos vinte anos muda-se para Naumberg onde trabalha na realização das estátuas duas estátuas de dois dos patronos fundadores daquela Igreja: Uta e Ekkehard II (CHAFES, 2012, p. 12). E passados 140 anos muda-se para Itália:

Sentindo-me muito curioso pelo que estaria a acontecer no 'berço do ocidente', do outro lado dos Alpes, dirigi-me a Itália onde em Lucca, por volta de 1406 a 1407, tive a enorme ventura de trabalhar na execução do Túmulo de Llaria del Carretto, do mestre Jacopo Dealla Quercia. [...] A sua escultura possuía uma qualidade formal irrepreensível aliada a uma serenidade e sentido de Beleza inultrapassável (CHAFES, 2012, p. 15-16).

Poder-se-ia ler o texto fazendo um mapa dos diferentes elementos que Rui Chafes aprende com os diferentes mestres. Se com Quercia aprende a qualidade formal que leva à Beleza com o seu mestre posterior, Tilman Riemenschneider (1460-1531) aprende o movimento e a delicadeza do corpo esculpido. Trata-se da lição da perfeição dos objectos e que é a condição da ideia escultórica poder ser transmitida.

Foram dias inesquecíveis em que a honra e o privilégio de trabalhar com aquele que eu considerava o maior Mestre-Escultor de toda a Alemanha me encheram da maior alegria que se pode ter: saber que se está a tomar parte, mesmo que ínfima, na criação de um momento de eternidade, de um momento em que a superfície da pedra ou da madeira ficará para sempre ferida pela luminosa violência da perfeição (CHAFES, 2012, p. 19).

Em 1530 o artista dirige-se à França onde trabalha em Tours com Jean Juste, segue depois para Roma em 1600 onde trabalha com Stefano Maderno e Bernini. Em 1808 já na Alemanha e depois do contacto intenso com Novalis, descobre Philip Otto Runge e aprende a importância do desenho e a sua centralidade no pensar e desenvolver a escultura. Quando finalmente regressa ao seu tempo, ao seu presente, Chafes afirma:

Nestes últimos anos [recorde-se que o texto está datado de 2011] tenho, finalmente, tentado trabalhar em coisas minhas, depois de tantos anos a trabalhar para os outros artistas. Aproveito tudo o que aprendi com eles, tudo o que me ensinaram, mesmo sem o querer (e sem o saber), como é comum acontecer em todas as aprendizagens e também em todas as escolas e universidades, não é verdade? Tento fazer, finalmente, o meu caminho (CHAFES, 2012, p. 34).

É notável como a cronologia estabelecida dilata o tempo do sujeito artístico Rui Chafes e faz da história da escultura, pelo menos da escultura que lhe interessa, a sua própria história. E a sua contemporaneidade não acontece através de um modo radical de negar, transgredir, 


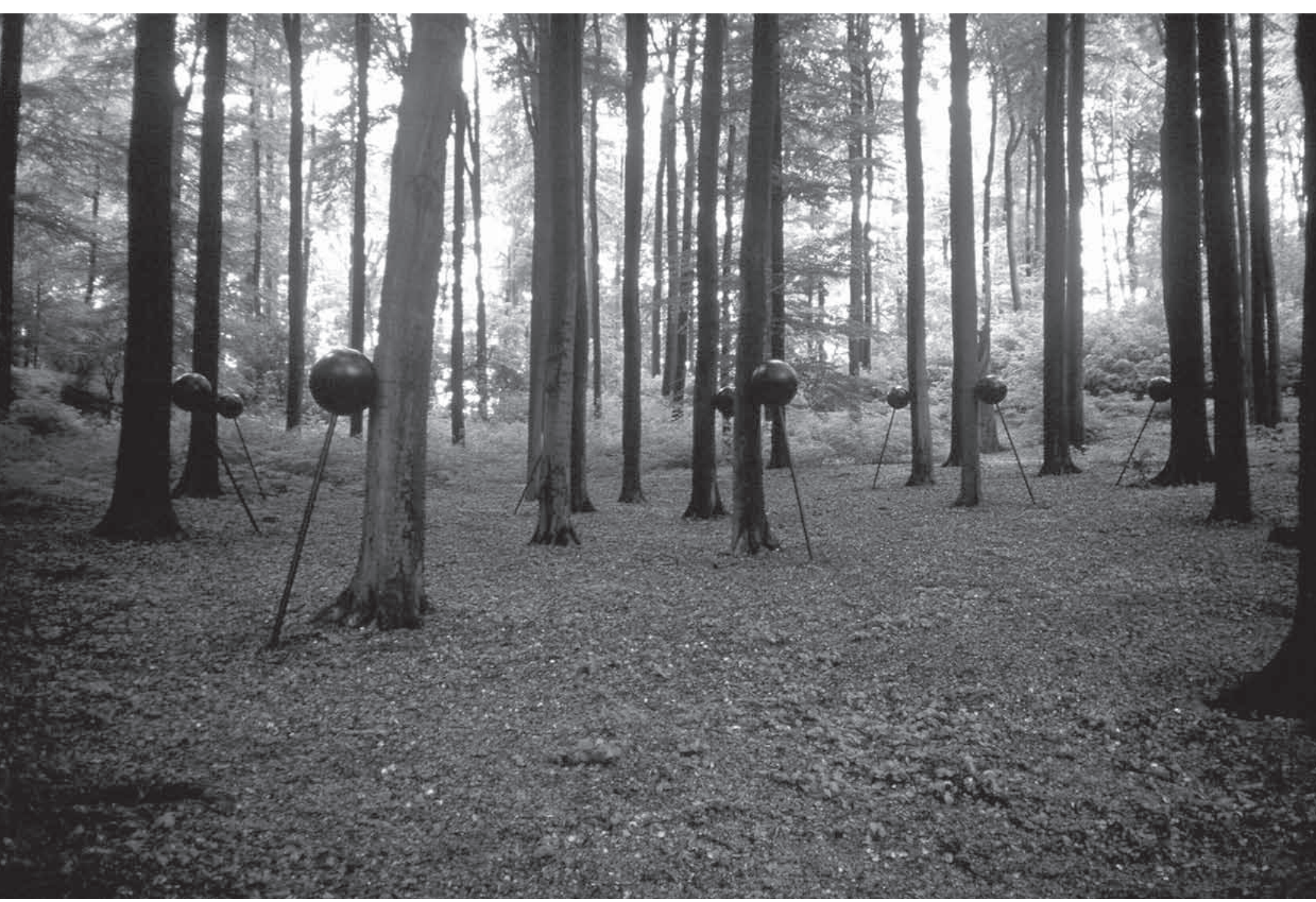

Rui Chafes

Unborn, 2001

Ferro, 9 esculturas, cada: $325 \times 65 \times 65 \mathrm{~cm}$

Col. Particular, Arnhem (Holanda) 
anular, esquecer, a sua herança artística e intelectual, mas pelo contrário pelo modo como através das suas obras se é levado para outros lugares, outros tempos, outras histórias: a sua vanguarda e a sua contemporaneidade são constituídas por um olhar para trás e as suas esculturas são formas plásticas e poéticas de interrogar a história. A sua contemporaneidade é, exactamente, o modo como torna actual certo passado, ou seja, a sua tentativa é a de fazer com que uma luz que vem de longe possa iluminar o presente. Poder-se-ia acrescentar muito mais ao modo como neste texto o artista torna contemporâneos posições escultóricas, aparente e teoricamente divergentes, através de um lugar virtual - as suas próprias esculturas — onde todos esses elementos se podem sentir simultaneamente. É como se cada escultura sua infectasse toda a história e trouxesse para o mesmo tempo todos os tempos da escultura.

\section{Conclusão: a contemporaneidade como leitura da história}

O artista contemporâneo é aquele que estando no presente a perceber o seu escuro e responde a esse escuro. Assim, pode entender-se o esforço artístico como uma resposta às trevas da hora (AGAMBEN, 2010, p.27).

$\mathrm{O}$ argumento que tentámos discutir ao longo deste texto pode sintetizar-se dizendo que a contemporaneidade artística é caracterizada por uma relação especial com o tempo e, dada essa relação que caracterizámos como sendo anacrónica porque o tempo da arte não tem medida, podem fazer-se corresponder às obras de arte a modos inéditos de ler a história porque cada obra de arte condensa, reorganiza e monta toda história. Cada uma dessas obras implica não só todo o tempo, mas a partir dela constitui-se certa tradição através da qual as obras permanecem luzes que tentam atingir a obscuridade do nosso presente.

Esta capacidade das obras e os artistas, mantendo-se vivos, atravessar o tempo traduz-se na relação dialéctica que a arte estabelece com o todo do tempo: as obras e os artistas são e não são de um tempo, pertencem a uma época, mas também são de todas as épocas, constituem uma tradição, mas estão disponíveis para a constituição de novas tradições. Trata-se de uma relação dialéctica que é consequência do anacronismo interno das obras de arte: o modo de ser da arte é a anacronia. E é esta sua modalidade constitutiva que possibilita aos artistas construirem o seu universo temporal — isto é, a sua contemporaneidade - , construção esta feita através de gestos plásticos, formais, materiais, poéticos, que simultaneamente estão no tempo e extrapolam o tempo integrando dimensões temporais inéditas, singulares e originais. 


\section{Notas}

1 "the condition of taking our current moment as the horizont and destination of our thinking",

2 "What I cal dialectical contemporary seeks to navigate mutiple temporalities within a more political horizon. Rather than simply claim that many or all times are presente in each historical object, we need to ask why certain temporalities appear in particular works of art as specific historical moments. Furthermore this analysis is motivated by a desire to understant our presente condition and how to change it. [...] The ultimate aim is do disrupt the relativist pluralism of the current moment, in which all styles and beliefs are considered equally valid, and to move towards a more sharply politicized understanding of where we can and should be headind of. If, as Osborne claims, the global contemporary is a shared fiction, then this doesn't denote its impossibility, but rather provides the basis for a new political imaginary."

3 "The contemporary becomes less a question of periodization or discourse than a method or practice, potentially applicable to all historical periods."

\section{Referências}

AgAMBEN, Giorgio, "O que é contemporâneo", in Nudez [Nudità, 2009], trad. port. Miguel Serras Pereira, Lisboa: Relógio D'Água Editores, 2010, p.20

BISHOP, Claire, Radical Museology or, What's 'Contemporary' in Museums of Contemporary Art?, London: Koenig Books, 2014.

DIDI-HUBERMAN, Georges Devant le temps. Histoire de L'art at anachronisme des images, Col. Critique, Paris: Les Éditions de Minuit, 2000.

CHAFES, Rui, "História da minha vida" in Entre o Céu e a Terra, Lisboa: Documenta, 2012

PELLBART, Peter Pál, , "What is the contemporary?", in Afterall. A jornal of art, contexto and enquiry, n 39, Summer 2015, London.

TSVIETAIVA, Marina, O poeta e o tempo, [Poet i Vremi, 1932], trad. Fernando Pinto do Amaral, Lisboa: Hiena Editora, 1993. 